\title{
Some aspects of dimeric metylsalicylatocopper(II) complexes preparation
}

\author{
Miroslava Puchoňová, Jozef Švorec and Dušan Valigura \\ Institute of Inorganic Chemistry, Technology and Materials, Faculty of Chemical and Food Technology STU, \\ Radlinského 9, 81237 Bratislava \\ miroslava.puchonova@stuba.sk
}

\begin{abstract}
A systematic study of the preparation of methylsalicylatocopper(II) complexes with or without $\mathrm{N}$-donor ligand has resulted in three new dimeric complexes formation. The investigation has been targeted to two main aspects: the conditions of dimeric complexes preparation and the properties of obtained products. The common stoichiometric formula for all three complexes is $\mathrm{Cu}(\mathrm{x}-\mathrm{MeSal})_{2}\left(\mathrm{H}_{2} \mathrm{O}\right)(\mathrm{ACN})_{2}($ where $\mathrm{x}-\mathrm{MeSal}=$ 3- or 4-methylsalicylate anion, ACN = acetonitrile and $\mathrm{z}=0,1$ ). Used spectral measurements mainly EPR spectroscopy gave the proof about the existence of dimeric "paddle-wheel" units in all three complexes. Moreover, it was concluded that acetonitrile molecules are more probably bonded to copper(II) atoms in apical positions of dimeric units. The water molecules are in coordination sphere only in the case when acetonitrile is not present. However data show that presence of 4-methylsalicylate anions led to strengthening of $\mathrm{Cu}-\mathrm{N}$ bonds.
\end{abstract}

Keywords: copper(II) complex, methylsalicylate ligand, dimeric complex, acetonitrile, EPR spectra

\section{Introduction}

The salicylic acid derivatives (e.g. Aspirin Fig. 1 - the first commercially introduced anti-inflammatory drug that is still in use) are well known for their different biological activities. Those activities were, from the early beginning, somehow related to the salicylate possible interactions with essential metallic microelements present in living body and later it was proved that the copper(II) aspirinate exhibits enhanced anti-inflammatory activity (Sorenson 1979) in comparison to aspirin itself.<smiles>CC(=O)Oc1ccccc1C(=O)O</smiles>

Scheme 1. Aspirin formula.

Many copper (II) complexes of pharmacologically active ligands have been shown to be more effective in treatment diseases than the parent ligands (Weder, Dillon 2002). Moreover, some copper (II) complexes including complexes of salicylic acid and its derivatives with basic ligands have been found to exhibit several other pharmacological effects suggesting possibility of treatment of many pathological disease states as inflammations, gastric and intestinal ulcers, diabetes, neoplasias carcinogenesis, convulsion, mutagenesis, ischemia-reperfusion injury (Abuhijleh 2010). On the other hand looking for possible explanation of the anti-inflamatory properties of aspirinate and/or salicylatecopper(II) complexes it has been concluded that both anions can favor gastrointestinal copper absorption, but they cannot increase plasma copper into tissue-diffusible complexes at drug plasma therapeutic level (Brumas 1995). Finally it was concluded that 3,5-diisopropylsalicylic acid might offer better model for study because free acid is inactive and it "becomes potent anti-inflamatory agent when associated with copper". Study of diisopropylsalicylatocopper(II) complexes has revealed (Morgant 2000) their dimeric structures, but it is not clear if their biological activity is related to their structure or to the hydrophobicity of the complex molecules. And therefore further study of preparation of copper(II) complexes containing similar ligands (e.g. methylsalicylate) is so important. In this paper we present preparation and spectral characterization of the $\mathrm{Cu}(\mathrm{x}-\mathrm{MeSal})_{2}\left(\mathrm{H}_{2} \mathrm{O}\right)(\mathrm{ACN})_{7}$ complexes (where $\mathrm{x}$-MeSal $=3$ - or 4-methylsalicylate anion, $\mathrm{ACN}=$ acetonitrile and $\mathrm{z}=0,1)$ that probably consists of the dimeric units $\mathrm{Cu}_{2}(\mathrm{x}-\mathrm{MeSal})_{4}$.

\section{Experimental}

\section{Synthesis of complexes}

$\mathrm{Cu}(3-\mathrm{MeSal})_{2}\left(\mathrm{H}_{2} \mathrm{O}\right)(1)$

Methylsalicylic acid (153 mg, 1mmol) was added to aqueous solution of copper(II) acetate $(5 \mathrm{ml}$, $0.5 \mathrm{mmol}$ ) under stirring and then was added $5 \mathrm{ml}$ ethanol. The reaction mixture was stirred at laboratory temperature until the reaction finished. The green precipitate was filtered and dried in air at ambient temperature. Mother liquid was left to 
crystallize at laboratory temperature. The obtained crystals were unsuitable for X-ray structure determination. The final product was characterized by available spectral methods including infrared spectra, UV-VIS, EPR spectra and elemental analysis.

Anal Calc for $\mathrm{Cu}(3-\mathrm{MeSal})_{2}\left(\mathrm{H}_{2} \mathrm{O}\right)$ : C, 49.6; H, 4.2. Found: C, 47.9; H, 4.5.

$\mathrm{Cu}(x-\mathrm{MeSal})_{2}\left(\mathrm{H}_{2} \mathrm{O}\right)(\mathrm{ACN})(2) x=3,(3) x=4$

Copper(II) acetate $(0,1 \mathrm{~g}, 0.5 \mathrm{mmol})$ was added to acetonitrile under stirring. Methylsalicylic acid (153 mg, 1mmol) was added to solution. The reaction mixture was stirred at laboratory temperature until the reaction finished. The pure solution was left to crystallize at laboratory temperature. The obtained crystals were unsuitable for X-ray structure analysis therefore the sample was characterized by available spectral methods (infrared spectra, elemental analysis, EPR spectra).

Anal Calc for $\mathrm{Cu}(3-\mathrm{MeSal})_{2}\left(\mathrm{H}_{2} \mathrm{O}\right)(\mathrm{ACN})$ : C, 52.6; H, 4.6; N, 3.4. Found: C, 50.6; H, 4.4 N, 3.2. Anal Calc for $\mathrm{Cu}\left(4-\mathrm{MeSal}_{2}\left(\mathrm{H}_{2} \mathrm{O}\right)(\mathrm{ACN})\right.$ : C, 52.6; H, 4.6; N, 3.4. Found: C, 51.8; H, 3.9 N, 2.7.

\section{Apparatus and equipment}

Analytical grade (Aldrich, or Sigma) chemicals were used without further purification. Carbon, hydrogen and nitrogen analyses were carried out on a CHNSO FlashEA ${ }^{\mathrm{TM}} 1112$ Automatic Elemental Analyzer.

The infrared spectra $\left(4000-400 \quad \mathrm{~cm}^{-1}\right)$ were measured with a NICOLET 5700 FT-IR (Nicolet) spectrophotometer at room temperature using ATR technique.

The electronic spectra $(190-1100 \mathrm{~nm})$ of the complexes were measured in nujol suspension with a SPECORD 200 (Carl Zeiss Jena) spectrophotometer at room temperature.

EPR spectra were measured at room temperature in the polycrystalline form with a spectrometer Bruker EMX series operating at X-band with an ER 035 NMR gaussmeter and a System Donner EMX frequency counter.

\section{Results and discussion}

Three new $\mathrm{x}$-methylsalicylatocopper(II) (where $\mathrm{x}=3$ or 4 ) complexes of unusual green colour were prepared by proposed changing of solvent from water to water-ethanol $1: 1(\mathrm{v} / \mathrm{v})$ mixture, or to acetonitrile. Using water as a solvent in the case of methylsalicylate complexes preparation leads (in spite of slightly acidic reaction conditions) frequently to the formation of light blue, or blue-greenish products mostly of hydrolytic origin (Repická 2011). All green products have been obtained reproducibly and the composition of the green product obtained from water-ethanol medium was consistent with formula $\mathrm{Cu}(3-\mathrm{MeSal})_{2}\left(\mathrm{H}_{2} \mathrm{O}\right)(\mathbf{1})$, while both products obtained from the acetonitrile medium exhibited according to elemental analyses the presence of nitrogen and their stoichometric formulae were $\mathrm{Cu}(\mathrm{x}-\mathrm{MeSal})_{2}\left(\mathrm{H}_{2} \mathrm{O}\right)(\mathrm{ACN})(2) \mathrm{x}=3$, or $(3) \mathrm{x}=4$.

All three green products showed the broad asymmetric absorption bands around $700 \mathrm{~nm}(712 \mathrm{~nm}$ for both complexes with 3-Mesal anions and about $700 \mathrm{~nm}$ for 4-Mesal complex) with unresolved shoulders further on the lower energy side. Moreover there were poorly resolved shoulders on the LMCT bands (at about $380 \mathrm{~nm}$ ) that are typical for the presence of the "paddle-wheel" structural units in the samples.

The presence of water in all three complexes was confirmed by infrared spectra (Table 1) but the differences were not significant enough for conclusion concerning the presence of water molecules in or out of the copper(II) atom coordination sphere. The broad bands bellow $3300 \mathrm{~cm}^{-1}$ confirmed the presence of salicylate $\mathrm{O}-\mathrm{H}$ group and their participation in hydrogen bonds formation that could be found in area close to $3000 \mathrm{~cm}^{-1}$. The absence of $\mathrm{C}=\mathrm{O}$ vibrations (around $1650 \mathrm{~cm}^{-1}$ ) and the presence of OCO vibration bands, shown in Table 1, proved that carboxylate groups are in all three complexes probably bonded in symmetric bidentate bonding mode.

Tab. 1. Infrared spectra data $\left(\mathrm{cm}^{-1}\right)$.

\begin{tabular}{lccccc}
\hline Compound & $v_{\text {as }}\left(\mathrm{COO}^{-}\right)$ & $v_{\mathrm{s}}\left(\mathrm{COO}^{-}\right)$ & $\Delta v\left(\mathrm{COO}^{-}\right)$ & $v(\mathrm{C} \equiv \mathrm{N})$ & $v(\mathrm{O}-\mathrm{H})$ \\
\hline $\mathrm{Cu}(3-\mathrm{MeSal})_{2}\left(\mathrm{H}_{2} \mathrm{O}\right)(\mathbf{1})$ & 1606 & 1430 & 176 & - & $3470 \mathrm{sh}$ \\
$\mathrm{Cu}(3-\mathrm{MeSal})_{2}\left(\mathrm{H}_{2} \mathrm{O}\right)(\mathrm{ACN})(\mathbf{2})$ & \multirow{2}{*}{1606} & 1426 & 180 & $2289 \mathrm{w}$, & $3403 \mathrm{~m}$ \\
& & & & $2260 \mathrm{w}$ & $3364 \mathrm{~m}$ \\
$\mathrm{Cu}(4-\mathrm{MeSal})_{2}\left(\mathrm{H}_{2} \mathrm{O}\right)(\mathrm{ACN})(\mathbf{3})$ & 1593 & 1421 & 172 & $2304 \mathrm{w}$, & $3500 \mathrm{w}$ \\
& & & & $2282 \mathrm{w}$ & $3408 \mathrm{w}$ \\
\hline
\end{tabular}


The two products of general formula $\mathrm{Cu}(\mathrm{x}$ MeSal $)_{2}\left(\mathrm{H}_{2} \mathrm{O}\right)(\mathrm{ACN})$, where $\mathrm{x}=3$ or 4 obtained from acetonitrile contain the solvent molecule in coordination sphere. In addition to abovementioned $\mathrm{O}-\mathrm{H}$ group and both asymetric and symetric $\mathrm{COO}^{-}$ vibrations, IR spectra also contained two other weak absorption bands of the $\mathrm{C} \equiv \mathrm{N}$ vibration (Table 1) that are higher than value $2254 \mathrm{~cm}^{-1}$ found for free acetonitrile (Fairlie 1997). This information could be taken as a proof that acetonitrile molecules are bonded to copper atoms in axial positions of dimeric $\mathrm{Cu}_{2}(\mathrm{x}-\mathrm{MeSal})_{4}$ structure similarly as it was found for the complex $\left[\mathrm{Cu}_{2}(\mu-4 \mathrm{Brbz})_{4}(\mathrm{ACN})_{2}\right]$ (Medvecká 2012) where the $\mathrm{Cu}-\mathrm{N} \equiv \mathrm{CCH}_{3}$ was proved by $\mathrm{X}$-ray structure determination. On the other hand, the complex $\left[\mathrm{Cu}_{2}\left(\mu-2 \mathrm{NO}_{2} \mathrm{bz}\right)_{4}(\mathrm{nia})_{2}\right] \mathrm{ACN}$ (Moncol 2010) containing acetonitrile molecules in the cavities between the dimeric complex molecules exhibits single vibration band at $2323 \mathrm{~cm}^{-1}$.

Another proof of the presence of acetonitrile nitrogen atom in the copper(II) coordination sphere could be found in FAR IR spectra where the bands around $300 \mathrm{~cm}^{-1}\left(293 \mathrm{~cm}^{-1}\right.$ for $(2)$ and $316 \mathrm{~cm}^{-1}$ for (3), respectively) could be tentatively attributed to $v(\mathrm{Cu}-\mathrm{N})$ vibration (Nakamoto 2009). Similarly for $\left[\mathrm{Cu}_{2}(\mu-4 \mathrm{Brbz})_{4}(\mathrm{ACN})_{2}\right]$ the corresponding band was found at $297 \mathrm{~cm}^{-1}$ (Medvecká 2012).

Powdered EPR spectra of all three complexes exhibit features which are typical for triplet state in the system with $S=1$. These spectra were simulated and characterized by means of spin Hamiltonian in the form (1)

$$
\begin{aligned}
& \hat{\mathbf{H}}=g_{\|} \beta H_{z} \hat{S}_{z}+g_{\perp} \beta\left(H_{x} \hat{S}_{x}+H_{y} \hat{S}_{y}\right)+ \\
& +D\left[\hat{S}_{z}^{2}-1 / 3 S(S+1)\right]+E\left(\hat{S}_{x}^{2}-\hat{S}_{y}^{2}\right)
\end{aligned}
$$

where $D$ is axial parameter of zero field splitting and $E$ stands for rhombic parameter of zero field splitting and other symbols have their usual meaning (Mabbs 1992). This pattern of the spectra is characteristic for "paddle-wheel" unit of dimeric carboxylato-bridged copper complexes. In this type of axial dimeric spectrum three from four resonances are present namely $B_{\mathrm{z} 1}, B_{\mathrm{xy} 2}$ and $B_{\mathrm{z} 2}$. The $B_{\mathrm{xyl}}$ resonance is not visible in X-band spectra due to the fact that microwave quantum is comparable with axial zero field splitting $D\left(\cong 0.3 \mathrm{~cm}^{-1}\right)$
(Bleaney 1952). The parameters of spin Hamiltonian obtained by computer simulation are listed in Table 2 and the EPR spectra under study are shown in Fig. 1, Fig. 2 and Fig. 3. Moreover in the case of EPR spectrum of (2) there were in addition to allowed resonances also the bands coming from monomeric impurity (Ozarowski 2008, Ozarowski 2009, Buvaylo 2011). Simulation of this monomeric impurity revealed the axial symmetry of EPR signal with $g_{\|}=2.382$ and $g_{\perp}=2.067$ and resolved hyperfine splitting in parallel part of the signal $A_{\|}=144$ Gauss (inset Fig. 2). The similarity between $g$ factors (Table 2) corresponding to the monomeric and dimeric copper ions indicates that monomeric impurity can be considered as a precursor of the dimeric ion (Buvaylo 2011).
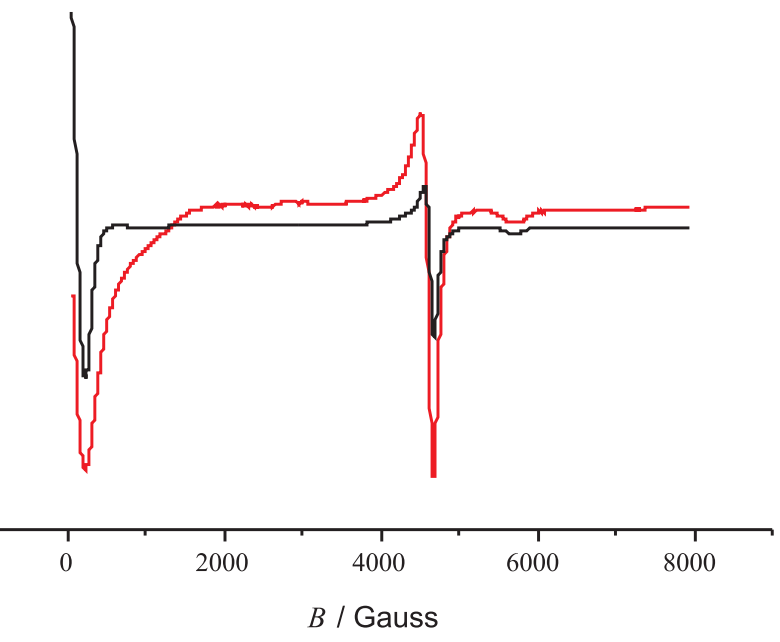

Fig. 1. EPR spectrum of $\mathrm{Cu}(3-\mathrm{MeSal})_{2}\left(\mathrm{H}_{2} \mathrm{O}\right)(1)$ (meas.—, calc. —)

In spectra of (1) and (3) the signals of monomeric impurities are not clearly resolved. The EPR parameters of all three complexes are very similar together which could be assigned to the presence of structural arrangement of paddle wheel unit.

Historically these parameters could be compared to those of copper acetate monohydrate $\left(g_{\mathrm{z}}=2.055\right.$, $g_{\mathrm{y}}=2.079, g_{\|}=2.364, D=-0.335 \mathrm{~cm}^{-1}$ and $E=-0.0103 \mathrm{~cm}^{-1}$ ) because this compound was the first studied among the carboxylates (Bleaney 1952, Ozarowski 2008).

The only difference in the parameter of the Spin Hamiltonian is in the value of $D$ parameter. For

\begin{tabular}{|c|c|c|c|c|c|}
\hline Compound & $g_{\|}$ & $g_{\perp}$ & $g_{\text {mon }}$ & $g_{\mathrm{av}}$ & $\mathrm{D} / \mathrm{cm}^{-1}$ \\
\hline $\mathrm{Cu}(3-\mathrm{MeSal})_{2}\left(\mathrm{H}_{2} \mathrm{O}\right)(\mathbf{1})$ & 2.389 & 2.063 & - & 2.172 & -0.321 \\
\hline $\mathrm{Cu}(3-\mathrm{MeSal})_{2}\left(\mathrm{H}_{2} \mathrm{O}\right)(\mathrm{ACN})(\mathbf{2})$ & 2.382 & 2.067 & 2.172 & 2.172 & -0.325 \\
\hline $\mathrm{Cu}(4-\mathrm{MeSal})_{2}\left(\mathrm{H}_{2} \mathrm{O}\right)(\mathrm{ACN})(\mathbf{3})$ & 2.391 & 2.064 & - & 2.173 & -0.337 \\
\hline
\end{tabular}

Tab. 2. EPR spectra parameters. 


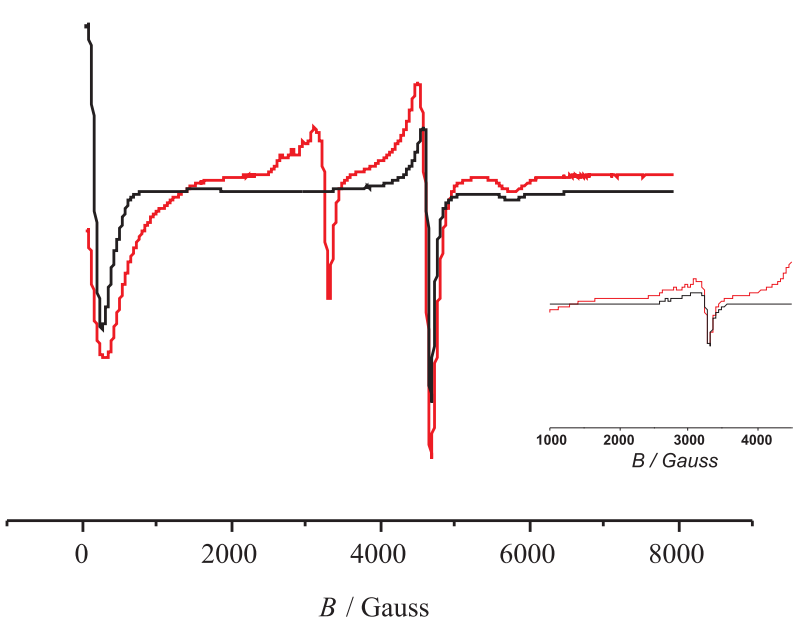

Fig. 2. EPR spectrum of $\mathrm{Cu}(3-\mathrm{MeSal})_{2}\left(\mathrm{H}_{2} \mathrm{O}\right)(\mathrm{ACN})$ (3) (meas. $\longrightarrow$, calc. $\longrightarrow$ )

Inset: Simulation of the monomeric impurity.

(3) the value of $D$ parameter is $-0.337 \mathrm{~cm}^{-1}$ in accordance with copper acetate value whereas for complexes (1) and (2) the values are noticeably lower and are equal -0.321 and $-0.325 \mathrm{~cm}^{-1}$ respectively. The explanation of this observation can be attributed to the electronic effect of the anionic ligands that contain methyl group located in position 4 in complex $\mathbf{3}$ contrary to complexes $\mathbf{1}$ and 2 where methyl groups are in position 3 . It should be noticed, that FAR IR $\mathrm{Cu}-\mathrm{N}$ vibration for $(\mathbf{3})$ is noticeably higher than in other two complexes giving some idea concerning the origin of the axial distortion.

In conclusion it should be stressed that changing the solvent used for sample preparations allowed us to prepare three new dimeric $\mathrm{x}$ methylsalicylatocopper(II) complexes containing the solvent molecules in central atom coordination sphere. The presence of dimeric structure was proved by UV/Vis and EPR spectroscopy. Moreover our findings confirm, that less polar solvents can prefer dimeric structure formation and the acetonitrile as aprotic solvent can significantly lower some hydrolytic product formation.

\section{Acknowledgement}

This work was supported by courtesy of the Slovak Grant Agency (VEGA 1/0052/11).

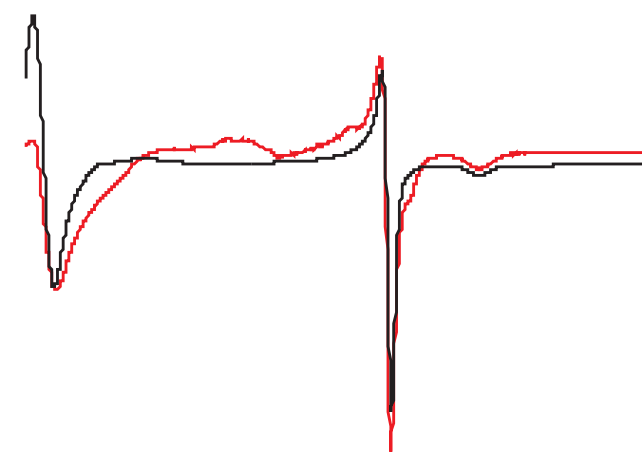

\begin{tabular}{cccc}
\hline 0 & 4000 & 6000 & 8000 \\
& $B /$ Gauss
\end{tabular}

Fig. 3. EPR spectrum of $\mathrm{Cu}(4-\mathrm{MeSal})_{2}\left(\mathrm{H}_{2} \mathrm{O}\right)(\mathrm{ACN})$ (3) (meas.—, calc.—).

\section{References}

Abuhijleh AL (2010) J. Mol. Struct. 980: 201-207.

Bleaney B, Bowers KD (1952) Proc. R. Soc. London A 214: 451-465.

Brumas V, Brumas B, Berthon G (1995) J. Inorg. Biochem. 57: 191-207.

Buvaylo EA, Kokozay VN, Vassilyeva OY, Skelton BW, Jezierska J, Ozarowski A (2011) Inorg. Chim. Acta 371: $1-5$.

Fairlie DP, Jackson WG, Skelton BW, Wen H, White AH, Wickramasinghe WA, Woon TC, Taube H (1997) Inorg. Chem. 36: 1020-1028.

Mabbs FE, Collison D (1992) Electron Paramagnetic Resonance of $d$-Transition Metal Compounds, Elsevier Science Publishers B.V., Amsterdam.

Medvecká J (2012) PhD thesis, STU Bratislava.

Moncol' J, Vasková Z, Stachová P, Švorec J, Silanpää R, Mazúr M, Valigura D (2010) J. Chem. Crystallorg. 40: 179 .

Morgant G, Dung N-H, Daran J-C, Viossat B, Labouze X, Roch-Aiveiller M, Greenaway FT, Cordes W, Sorenson JRJ (2000) J. Inorg. Biochem. 81: 11-22.

Nakamoto K (2009) Infrared and Raman spectra of inorganic and coordination compounds, Part B, Sixth Ed. Wiley 118-120.

Ozarowski A (2008) Inorg. Chem. 47: 9760-9762.

Ozarowski A, Szymanska IB, Muziol T, Jezierska J (2009) J. Am. Chem. Soc. 131: 10279-10292.

Sorenson JRJ (1976) J. Med. Chem. 19: 135-148.

Weder JE, Dillon CT, Hambley TV, Kennedy BJ, Lay PA, Biffin JR, Regtop HL, Davies NM (2002) Coord. Chem. Rev. 232: 95-126. 